\title{
History, Virulence Genes, Identification and Antimicrobial Resistance of Enterococcus faecalis Isolated from Diabetic Foot Patients
}

\author{
Ahmad Abdulrahman AL Bloushy ${ }^{1,2 *}$ and Ayman Elbehiry ${ }^{3,4}$ \\ ${ }^{1}$ Al Bukayriyah General Hospital, Qassim, Kingdom of Saudi Arabia \\ ${ }^{2}$ Department of Botany and Microbiology, College of Science, King Saud University, \\ P.O. Box 2455, Riyadh 11451, Saudi Arabia \\ ${ }^{3}$ Department of Bacteriology, Mycology and Immunology, Faculty of Veterinary Medicine, \\ Sadat City University, Sadat, Egypt \\ ${ }^{4}$ Department of Public Health, College of Public Health and Health Informatics, Qassim \\ University, Buraidah, Saudi Arabia \\ *Corresponding author
}

\section{A B S T R A C T}

\begin{tabular}{|l|}
\hline Ke y w o r d s \\
Virulence genes, \\
$\begin{array}{l}\text { Enterococcus } \\
\text { faecalis }\end{array}$ \\
\hline Article Info \\
\hline $\begin{array}{l}\text { Accepted: } \\
\text { 16 December } 2017 \\
\text { Available Online: } \\
\text { 10 January } 2018\end{array}$ \\
\hline
\end{tabular}

\section{Enterococci}

Enterococcus is a large genus of lactic acid bacteria that have the ability to grow under various aggressive conditions. Enterococci are Gram-positive cocci that often occur in pairs (diplococci) or short chains, and are difficult to distinguish from streptococci on physical characteristics alone (Gilmore et al., 2002). Enterococcus species are facultative anaerobic

\begin{abstract}
Diabetic foot infections (DFIs) is a chronic form of diabetes mellitus (DM) associated with a high economic and social problem worldwide. Approximately $60 \%$ of these amputations is preceded by the presence of infected ulcers. Recently, Enterococci, mainly Entrococcus feacalis (E. faecalis), is considered one of the most frequent microorganisms isolated from hospital associated infections in in many parts of the world. The aim of this manuscript is to provide a present concept review on the history of infections, virulence genes, identification and antimicrobial resistance of E. faecalis isolated from patients suffering from diabetic foot infections which are considered the most thoughtful and common problems encountered in patients with diabetes mellitus. A literature review on E. faecalis with emphasis on history of diseases, virulence genes, anti-microbial resistance and identification methods has been carried out in details.
\end{abstract}

organisms that can survive at $60^{\circ} \mathrm{C}$ for short times and can grow in high salt concentrations. Recently, the genus Enterococcus is composed of thirty-eight species, Enterococcus faecalis (E. faecalis) and Enterococcus faecium (E. faecium) are considered the most common commensal two species normally inhabitant in the intestine of both humans and animals.(Gilmore et al., 2002; John and Carvalho, 2011). Up to 1984 , 
E. faecalis was recognized as Streptococcus faecalis. Formerly researchers considered this bacterium as part of the genus Streptococcus. As stated by the Centers for Disease Control and Prevention (CDC), E. faecalis is responsible for about $80 \%$ of human infections.

\section{History of Enterococcus feacalis diseases}

Enterococci are opportunistic microorganisms that become pathogenic due to defect in the immune system. Currently, (Olawale et al., 2011) illustrated that Enterococcus species have the ability to cause hospitalized infections, especially of the urinary tract, surgical sites, and blood stream. Moses et al., (2012) indicated that Enterococcus are considered the third isolated organism between hospitalized infections in the USA and the most common isolated microorganisms in blood stream. Enterococci are also considered one of main causes of infectious endocarditis after staphylococci and streptococci. Approximately $90 \%$ enterococcal endocarditis are caused by E. faecalis, with fewer than 5\% affected by E. faecium. The morbidity and mortality of enterococcal endocarditis are high. The proportion of patients demanding cardiac operation $42 \%$ and the 1-year mortality ratio $29 \%$ have endured almost unaffected for the previous 30 years, and modern data demonstration that they may even be increasing (Miro et al., 2013).

Primarily in the last two decades; these strains have occurred in hospitalized infections in the United States. In a previous study, Vancomycin Resistant Enterococci (VRE) form approximately $43 \%$ of all the enterococci isolates, a sum that is in height when one reflects the fact that vancomycin is not presented for clinical usage in Nigeria. The VRE isolates include two E. faecalis and the one E. faecium were isolated and resistant to eight tested antibiotics (Olawale et al.,
2011).The high prevalence of Enterococci has developed as a public health threat. Anvarinejad et al., (2015) indicated that the Enterococci are the most common bacteria present in immune-compromised patients, such as diabetics, and in their foot ulcers, but their part in corruptions at these sites is not clearly detected.

\section{Diabetic foot infections}

Diabetic foot (DF) is a chronic form of diabetes mellitus (DM) associated with a high economic and social problem. The danger of emerging a foot ulcer in a patient with diabetes ranges from $15 \%$ to $25 \%$ (Doria et al., 2016). Diabetic Foot Ulcer (DFU) represents one of the major problems of Diabetes Mellitus (DM) with a yearly incidence of $10 \%$ among diabetic patients. It is calculated that $15 \%$ of diabetic patients are suffering from ulcers through their lifetime, and $10-30 \%$ of these cases ultimately develop to an amputation. The rate of infections is a significant causative issue for this case, as according to this review of literature; about $60 \%$ of these amputations is preceded by the presence of infected ulcers. The mortality after 5 years in patients suffering of a lower limb amputation is ranged from50\% to60\% (Perich et al., 2010; Berlanga et al., 2005). Most Diabetic foot infections (DFIs) require a polybacterial etiology, presence of enterococcal strains as part of the multifaceted diabetic foot microbiota. Former studies pointed to that the Enterococcus genus is one of the greatest gram positive pathogenic microorganisms in DFI samples (SemedoLemsaddek et al., 2016).

The diabetic patients are approximately 366 million worldwide and it is expected to exceed half billion by 2030 (Quilici et al., 2016). Foot ulcers are one of the major health concerns and hospitalization among patients with diabetes, worldwide. In the USA, the yearly 
price of foot ulcers is estimated at US\$11 billion (Brechow et al., 2013). In Brazil, the population 30 years old and over with type 2 diabetes is calculated at 6.5 million. Rezende et al., (2010) clarified that about 323000 cases of foot ulcers were recorded yearly, 97 thousand of which need hospitalization. Addition to the prices of handling infection, diabetic patients is suffered from the danger of limb amputation, with rates of about 40timescomplex than in persons of normal cases. Several studies have explained the incidence of diabetic foot to be on the order of (3- 4\%), accounting for unevenly 11 million patients with this complaint in 2014 (Santos et al., 2013).

The controlling of both obesity and diabetes and their associated problems is considered as a substantial economic burden. McInnes, (2012) indicated that the yearly cost of diabetic foot disease to healthcare agencies in the United Kingdom (UK) exceeds $£ 732$ million equating to $£ 1$ in every $£ 150$ of the NHS financial plan. Throughout the high incidence of these circumstances, these costs are likely to intensify. Control of diabetic patients plays an important role in reducing the danger of emerging micro-vascular problems (UK Prospective Diabetes Study Group, 1998). A reduction in weight has been exposed to develop glycaemic controller, and weight loss is now considered as one of the strength steps of management in type 2 diabetes (Gooday et al., 2014).

Aerobic gram-positive cocci are the main bacteria that colonize and extremely infect skin (Mathangi and Prabhakaran, 2013; Hartemann- Heurtier et al., 2004). A total of 86 diabetic patients were investigated and Enterococcus spp. were frequently isolated from $34(39.5 \%)$ patients consisting of 20 males (59\%) and 14 females (41\%), and showed a high degree of resistance to vancomycin. Knowing of the causative microbes in Diabetic Foot Infections (DFIs) and their antibiotic susceptibility profiles is an important step for an appropriate treatment and eradication of infection (Anvarinejad et al., 2015). In Portugal all Enterococcus species isolated from diabetic foot infections were considered as resistant to different antibacterial agents, gelatinase and cytolysin creators, and the majority also established the aptitude to harvest biofilms these consequences show the importance of enterococci in diabetic foot infection advance and persistence, particularly concerning their biofilm forming aptitude and resistance to clinically pertinent antibiotics (SemedoLemsaddek et al., 2016). Currently, enterococci have developed one of the greatest public nosocomial infections, with patients having a great mortality rate of about $61 \%$ Fisher and Phillips (2009).

Additionally, wound and soft tissue infections due to Enterococcus spp. are progressively increase. Risk factors for colonization and infection include earlier use of antibiotics. Nevertheless, data concerning the soft tissue and wound infections due to Enterococcus spp. and its resistance form among traumatic patients are uncommon (Rajkumari et al., 2014). Enterococcus genusis considered as one of the common gram positive pathogenic bacteria in DFIs samples, causative to the tenacity or cruelty of the disease and principal to higher morbidity and mortality degrees (Lipsky et al., 2013). (Alzahrani et al., 2013) reported that more researches on DFDs are needed in maximum of the Arabs' republics predominantly those in the Gulf Cooperation Council (GCC) area which informed very high incidence degrees and are predictable to hold these degrees for the next years.

\section{Cellulitis}

The historical cellulitis is usually defined as a non-necrotizing infection of the skin and 
subcutaneous tissues, frequently from acute infection. Cellulitis commonly monitors a breach in the skin, although a portal of entry may not be visible; the breach may include microscopic skin changes or invasive abilities of certain microorganisms. Skin and soft tissue infections without a clear trauma, scar, drainage, or abscess is mainly caused by streptococci, Staphylococcus aureus, and community acquired Methicillin Resistant Staphylococcus aureus (MRSA), is most common pathogen of this infection (Stevens et al., 2014).

\section{Deep skin and soft tissue infections}

Skin and soft tissue infections (SSTIs) are a significant reason of high morbidity and mortality rates among nosocomial infections and are considered as a main therapeutic research for clinicians. SSTIs are similarly an important cause for life threatening bacteremia and metastatic abscesses. Gram positive bacteria, such as S. aureus and S.pyogenes, represent the primary isolated bacteria from SSTIs, while gram negative bacteria are originating in chronic wound infections Cardona and Wilson (2015). Among culture established SSTIs in the USA, the frequent bacterial reason is $S$. aureus, although $P$. aeruginosa, Enterococcus spp., E. coli, and BHS have also been recognized as significant sources of certain types of SSTIs (Ray et al., 2013).

\section{Osteomyelitis}

Osteomyelitis is a provocative procedure relating cortical and cancellous bone. In the maxillofacial area, the jawbone is the major affected bone (Zemann et al., 2011). Recently, Enterococcus cecorum has been recognized as an emergent avian pathogen, related by spondylitis, femoral head necrosis, and osteomyelitis in broiler and broiler breeder flocks in Scotland (Stalker et al., 2010).
Enterococcus vertebral osteomyelitis is a rare infection that can occur by hematogenous spread from an infection of the urinary tract (Kow et al., 2014).

\section{Enterococcus virulence genes}

Enterococcus species have numerous virulence factors such as enterococcal surface protein (Esp) and aggregation substance (Agg) which increase the process of colonization in epithelial lining of the host cells (Soheili et al., 2014). Seventy-nine of Malaysian enterococci isolates were examined for the presence of different virulence genes. Soheili et al., (2014) found that pilB, fms8, efaAfm, and sgrA genes of Enterococci are predominant in all medical isolates. In addition, incidence of gene coding for Esp has been commonly identified in medical isolates than commensal isolates (Giridhara Upadhyaya et al., 2010).

The aggregation substance (Agg) is a pheromone inducible surface protein of Enterococcus faecalis essential for cell to cell connection throughout conjugation and for adhesion to eukaryotic cells. Medeiros et al., (2014) demonstrated that this protein facilitates aggregation of donor and recipient bacteria and supports the conjugative plasmid transmission throughout microbial conjugation. In Brazil the asa1, gelE and esp virulence genes were recognized in 38\%, 60\% $\& 76 \%$ of all isolates, correspondingly (Comerlato et al., 2013) and the first two genes were predominant in E. faecalis than in E. faecium. Moreover, various factors such as gelatinase, hemolysin, aggregation substance (AS), enterococcal surface protein (Esp), MSCRAMM Ace (microbial surface component recognizing adhesive matrix molecule adhesion of collagen from Enterococci), serine protease, cell wall polysaccharide, capsule and superoxide have been associated with the virulence of $E$. faecalis in animal models (Giridhara 
Upadhyaya et al., 2010). Gelatinase is a protease enzyme formed by E. faecalis. It is accomplished of hydrolyzing collagen, casein, hemoglobin and other peptides. Giridhara Upadhyaya et al., (2010) clarified that hemolysin is a cytolytic protein associated with of red blood cells of human, horse and rabbit origin. This protein is associated with the increasing severity of infections. Alternatively, in Portugal (SemedoLemsaddek et al., 2016), stated that the pathogenesis of foot ulceration is complicated, the death is excessive and ulcers are frequently occurred and lead to severe and chronic infections of the foot. Most DFIs have a poly-microbial etiology, enterococcal strains actuality portion of the multifaceted diabetic foot microbiota. The higher rate of E. faecalis among the diabetic foot ulcer enterococci relates to the predictable, as this species is reflected the highest pathogenic of this genus, being usually related with medical samples. El-Tahawy (2000), described that the frequency of Enterococci in diabetic foot infections in Saudi Arabian patients, has been increasing, and indicated that the high incidence might be due to former using of different. Whereas; in Turkey (Turhan et al., 2013), established that the second most frequent Gram positive bacterium was Enterococcus spp. With about 30\% isolated from diabetic foot ulcers.

Fischer and Phillips, (2009) found that he extracellular surface protein (Esp), encoded by the esp gene, is a cell wall-associated protein which contributes as adhesin for the pathogen to host tissue establishment and persistence in urinary tract infections. This protein is associated with increased virulence (Shankar et al., 1999). Furthermore, (Koch et al., 2004 and Lebreton et al., 2009) indicated that $E$. faecalis species contain a special type of protein called cell surface protein which is considered as adhesion of collagen (Ace), and play an important role in the association of microorganisms to host cell matrix proteins, for example collagen I, IV and laminin. Several studies on the pathogenesis of enterococci demonstrated that Ace protein may have a positive effect in. In India the different genes in responsible for virulence of Enterococcus species were identified by multiplex PCR and at smallest one of the five was noticed in all the scientific vancomycin resistant enterococci (VRE) and vancomycin sensitive enterococci (VSE). esp, gel E, and hyl genes were establish to be meaningfully advanced in medical VRE (Biswas et al., 2016). Of the fecal isolates, occurrence of esp, gel E, and asa1 was importantly greater in VRE as compared to VSE. In addition, in Turky the vanA MDR1 gene was noticed in all VRE isolates (Saba Copur et al., 2016). Furthermore, from the virulence genes, hylesp was discovered in E. faecium, an Enterococcus with the uppermost resistance to vancomycin, and gelE was discovered in $E$. faecalis, an Enterococcus with the maximum sensitivity to vancomycin. Three or more virulence genes were recognized only in VSE strains. We reflect that it is an important outcome that VSE had more virulence genes than VRE. Esp was only noticed in VRE E. faecium strains. In India, E. faecalis, 16 isolates $(12.9 \%)$ and 4 isolates $(3.2 \%)$ showed resistance to vancomycin and teicoplanin by disc diffusion correspondingly (Rengaraj et al., 2016). Van A was discovered in 2, van B in 7 and one had both van A and van B. In China, Sun et al., (2012) stated that E. faecalis showed vancomycin and teicoplanin MIC results at $\geq 256 \mu \mathrm{g} / \mathrm{mL}$ and harbored vanA, but for 1 vanB carrying strain (MIC, 32 and 1 $\mu \mathrm{g} / \mathrm{mL}$, correspondingly). In Pakistan, Yameen et al., (2013) informed that VRE presented resistance to teicoplanin and vancomycin together and none was resistant to linezolid and inupristin/dalfopristin. Frequently, MICs of vancomycin for adenoid and perirectal VRE were $512 \mathrm{mg} / \mathrm{L}$ and 64 to $512 \mathrm{mg} / \mathrm{L}$ separately. VRE were detected in 
patients with long-lasting hospitalization, from city areas and those having pneumonia. In Malaysia, Raja, (2007) indicated that $9 \%$ of Enterococcus spp. from 287 microorganisms isolated from diabetic foot infections. In India, Vinodkumar et al., (2011) found that a whole of $65.6 \%$ of Enterococcus spp. were isolated from diabetic foot infections with high level aminoglycoside resistance (HLAR). Multidrug resistance and associated resistance of HLAR strains to other antibiotics were moderately high. The nosocomial infection of Enterococcus species has increased in recent years, in addition to growing resistance to the glycopeptide vancomycin antimicrobial drugs. Understanding of ecology, epidemiology and virulence of Enterococcus spp. is significant for preventive numerous infections, and in addition stop the development of antimicrobial resistance Fisher and Phillips, (2009). The degree virulence and pathogenicity have been described by genotypic methods. Klibi et al., (2007) indicated that numerous genes isolated from resistant enterococci (agg, cpd, cylLLS, esp, gelE, ace, fsrB) were encoded to virulence factors for example the production of gelatinase and hemolysin, adherence to caco-2 and hep-2 cells, and ability for biofilm formation. Different isolates of E. faecalis and E. faecium exhibited varied strategies of virulence factors.). In India Bhatt et al., (2014) established that VanA gene was observed in all the fourteen isolates by Multiplex PCR. One of the PCR amplicons was directed for sequencing and the sequence established was submitted in the GenBank (GenBank accession no. KF181100).

\section{Mechanism of resistance to antimicrobials}

Resistance to various antibiotics is considered as a standard biological phenomenon. The plan of using each antibiotic as a therapeutic agent has been followed through the recognition in the lab of microbial strains that are resistant, i.e. capable to increase in the presence of drug cares greater than the attentions in humans getting therapeutic amounts Davies and Davies, (2010). Such resistance might be a characteristic associated with the entire species or occurs in the vulnerable strains by alteration or gene transfer. Resistance genes encode numerous devices which let bacteria to resist the inhibitory properties of exact antimicrobial agents Malachowa and DeLeo, (2010). Gram negative bacteria use four mechanisms of resistance to survive to the antibiotic treatment.

\section{Efflux of antibiotics from bacteria}

Enterococcus faecalis is supposed to have a high level of resistance to various types of antibiotics. Drug efflux pump proteins in microorganisms drop into five distinct proteins and they are typically encoded by chromosomal genes./The Colony blotting presented that the Enterococcus faecalis isolates protected multidrug efflux pump genes (Chouchania et al., 2012). Multidrug efflux pump concept, sanitization, and sequencing showed the spreading of mefA and $m s r \mathrm{~A} / m s r \mathrm{~B}$ efflux pumps.

\section{Outer membrane permeability}

Most of antibacterial agents enter the microbial cell to reach their target site wherever they can affect with the usual role of the microbial organism. Porin channels are the passages through which these agents would usually annoyed the microbial outer membrane. Certain microorganisms protect themselves by elimination these antimicrobial complexes from incoming past their cell walls. Diversities of Gram negative microorganisms decrease the uptake of various antimicrobial groups, for instance aminoglycosides and $\beta$ lactams groups, throughout the adaptation of the plasma membrane porin channel. denEngelsen et al., (2009) demonstrated that 
the prevention of these antimicrobials from achievement their actions, are based on the ribosomes and the penicillin binding proteins (PBPs).

\section{Modification of the antimicrobial target}

Several microbial species can resistant antibiotics through covering their target sites (Figure 1). Consequently, despite the presence of an entire and active antimicrobial complex, no subsequent binding or inhibition will take site Schmieder and Edwards (2012).

\section{Modification of the antimicrobial enzymatic activity}

Ampicillin and penicillin are considered the most common $\beta$-lactam antibiotics against enterococci by inhibiting the synthesis of peptidoglycan, which is one of the basic structures of the bacterial cell wall. Penicillinbinding proteins (PBPs) are the corner stones for synthesis of the cell wall of microbial cells and they can be classified into two main groups: class A, which are functional enzymes that composed, d-trans peptidase and trans glycosylase, and class $\mathrm{B}$, which have one the transpeptidase range and depend on the trans glycosylase action of other enzymes (Miller et al., 2014).

\section{Natural resistance}

Natural resistance is the innate aptitude of a microbial species to resist action of specific antibiotics and concluded its characteristic structural or useful characteristics, which permit tolerance of a specific drug or antimicrobial class, such as normal resistance of E coli to penicillin (Martinez, 2002).

\section{Acquired resistance}

Acquired resistance is occurring once specific bacteria obtain the aptitude to resist the action of a specific antibacterial agent to which it was earlier susceptible. van Hoek et al., (2011) stated that exert their action through the mutation of genes implicated in usual physiological procedures and cellular constructions, from the acquirement of external resistance genes or from a mixture of these two mechanisms, such as when E. coli resistant to ampicillin.

\section{Vertical gene transfer}

Assassination susceptible microorganisms while permitting strains with resistance to that specific antibiotic to live and grow. Characters for such resistance are then vertically delivered on to daughter cells thru cell division, then making a resistant populace which can then feast and be additional sources of resistance genes for other strains (Lawrence, 2005).

\section{Horizontal gene transfer}

The antibiotic resistance genes are transfer on plasmids, transposons or integrons that can performance as vectors that transmission these genes to other memberships of the same microbial species, as well as to microorganisms in additional genus or species.

Horizontal gene transmission may arise via three main techniques: transformation, transduction or conjugation (Vogan and Higgs, 2011). Antibiotic resistance has been acquired, and has dispersed through enterococci, via horizontal transfer of mobile genetic elements. This transfer has been facilitated mostly via conjugative plasmids of the pheromone-responsive and wide host range incompatibility group 18 types and lately they played a significant part in mediating transmission of vancomycin resistance from enterococci to methicillinresistant strains of Staphylococcus aureus (Palmer et al., 2010). 


\section{Vancomycin resistant enterococci (VRE)}

Vancomycin resistant enterococci (VRE) are a sort of microorganisms termed enterococci that have established resistance to numerous antimicrobial agents, particularly vancomycin. CDC, (2011) indicated that Enterococcus species live in our guts and on our skin, commonly without adverse effects nevertheless if they develop resistant to antibiotics, they can lead to grave infections, particularly in societies who are ill or weak. These infections can arise anywhere in the body. Certain common sites contain the guts, the urinary tract, and wounds. VRE exert its action when it attacks the bloodstream. Furthermore, it can be presented into a wound. Infection is additional possible in publics with chronic diseases like diabetes or patients who have lately received antibiotics. It is also further joint in patients with indwelling devices like intravenous lines or urinary catheters and those with compromised immune systems. When medical isolates of these enterococcal species with acquired vancomycin resistance initiated to show in the late 1980s, it encouraged significant changes in testing of enterococci in the medical microbiology laboratory, infection control of enterococci, and management of enterococcal infections (Eliopoulos and Gold, 2001). Driscol, Crank, (2015) in USA established that E. faecalis is considered the most common cause of joint infections, nevertheless $E$. faecium is an extra resistant to antibiotics with a half of nosocomial isolates in the US producing resistance to ampicillin and vancomycin. Rendering to the National HealthCare Safety Network (NHSN), from 2009 to 2010, (35.5\%) of enterococcal hospital related infections were resistant to vancomycin, ranking as the $2^{\text {nd }}$ greatest public reason of nosocomial infections in the US (Sievert et al., 2013). In contrast, Canada has a lesser frequency of VRE; rendering to CANWARD, $(6 \%)$ of enterococci in Canada were resistant to vancomycin from 2007 to 2011 (Zhanel et al., 2013; Lochan et al., 2016). In South African reported that VRE was found in 8 of 55 patients screened. Infected and colonized patients were isolated in the unit throughout their admission and strict interaction precaution infection control applies were established. The van $\mathrm{A}$ gene was recognized in all of the isolates (Tripathi et al., 2016).

In India found that $E$. faecalis $(72,61 \%)$ and E. faecium (46, 39\%). All 118 vancomycin resistant isolates were vanA genotype (minimum inhibitory concentration [MIC] to vancomycin $\geq 64 \mu \mathrm{g} / \mathrm{ml}$ and MIC to teicoplanin $\geq 32 \mu \mathrm{g} / \mathrm{ml}$ ) and none of the isolates was $\operatorname{van} B$ genotype. Multivariate logistic reversion analysis recognized ventilator provision and hospital stay for $\geq 48$ $\mathrm{h}$ as sovereign risk factors related with VR $E$. faecalis and VR E. faecium infection or colonisation. Hospital stay $\geq 48 \mathrm{~h}$ was the only sovereign risk factor for mortality in patients infected with vancomycin resistant enterococci. Amberpet et al., (2016) conveyed that Mainstream of the isolates were Enterococcus faecium (77.2 \%) followed by Enterococcus faecalis (23.8\%). All the VRE isolates were positive for vanA gene. Augmented period of hospital stay, younger age, consumption of ceftriaxone and vancomycin were established to be significantly related with VRE colonization in MICU. Amongst VRE colonized patients, (6, $4.5 \%)$ acquired VRE infection. Karimzadeh $e t$ al., (2016) in Iran reported that all Enterococcus spp. isolates within the 3 years were resistant to oxacillin. The rate of vancomycin resistant enterococci (VRE) augmented from $40.63 \%$ in 2013 to $72.73 \%$ in 2015. Enterococcus spp. resistance rates to aminoglycosides during 3 years were above $85 \%$.Hospitalization, surgical processes, and, particularly, lengthy or broad spectrum antibiotic treatment may dispose patients to 
colonization and/or infection with antibiotic resistant bacteria (e.g., MRSA or vancomycinresistant enterococci [VRE]) (HartemannHeurtier et al., 2004). Vancomycin (or glycopeptide) intermediate $S$. aureus has been isolated in numerous nations. Of note, the first 2conveyedsuitcases of vancomycin resistant $S$. aureus each implicated a diabetic patient with a foot infection CDC (2002). FURLANETOMAIA et al., (2014) in Sao Paulo found that all isolates of E. faecium and E. faecalis we observed $100 \%$ arrangement. Resistance incidences were advanced in E. faecium than $E$. faecalis the resistance degrees gained were greater for erythromycin $(86.7 \%)$, vancomycin $(80.0 \%)$, tetracycline (43.35) and gentamicin $(33.3 \%)$. The relationship between disk diffusion and automation revealed a convention for the plurality of the antibiotics with category agreement degrees of more than $80 \%$. In India, Bhatt et al., (2014) demonstrated that 14, (14.6\%) out of 96 Enterocoocus spp isolates, were resistant to vancomycin via vancomycin $\mathrm{E}$ test method (MIC32mg/ml).

\section{Phenotypes, genotypes of glycopeptide resistance in Enterococci}

Microbial cell walls are consisting of peptidoglycan that is made once cell wall pentapeptide precursors finish in D-Ala-D-Ala translocate subsequently the cytoplasm to the cell external and are combined into emerging peptidoglycan by trans-glycosylation, creating cross links via trans-peptidation to strengthen the cell wall (Mainardi et al., 2008).

The main report of enterococci resistant to great absorptions of glycopeptide antimicrobial agents such as vancomycin and teicoplanin was published in 1988, once Uttley et al., indicated that the incidence of an outbreak of vancomycin resistant E. faecium infecting patients in a hospital renal unit. In relation to glycopeptide resistance, there are six phenotypes, three of which are frequently arising. The VanA phenotype has an inducible high level of resistance to vancomycin in addition to teicoplanin (encoded by the VanA gene). The VanB phenotype (encoded by two vanB genes) has an excessive resistance to vancomycin only. The VanC phenotype (encoded by two vanC genes) reveals a noninducible squat level resistance to vancomycin (Eliopoulos and Gold, 2001).

Van A and Van B are the greatest clinically important phenotypes and are typically seen amongst E. faecalis and E. faecium isolates. Van $\mathrm{C}$ is both intrinsic and specific in $E$. gallinarum and E. casseliflavus. Since they are intrinsic relatively than acquired, they signify a dissimilar impact/significance for hospital epidemiology; final speciation can have import for infection control tenacities.

Recently, both ampicillin and vancomycin exert the most common resistance to $E$. faecium isolates than with E. faecalis. Forbes et al., (2014) indicated that vancomycin is highest $-E$. faecium strains which have the vanA gene. In 2002, the threat of VRE colonization and infections improved when the first patient case of VRE transmitting vanA resistance genes to methicillin-resistant Staphylococcus aureus (MRSA) to form a vancomycin-resistant Staphylococcus aureus (VRSA) isolate was detected (Chang et al., 2003).

Praharaj et al., (2013) illustrated that 32 out of 367 isolates of Enterococcus species isolated, were established resistant to vancomycin after MIC testing. VanA was the the most common phenotype of vancomycin resistance. An occurrence of heterogeneity in isolates of VRE with the vanA gene cluster with respects to resistance to teicoplanin and the cohabitation of vanA and vanC1 gene clusters in an isolate of E. gallinarum which allow a high level glycopeptide resistance to the isolate. 
Fig.1 Actions of antimicrobial resistance to different microorganisms. Schmieder and Edwards, (2012)

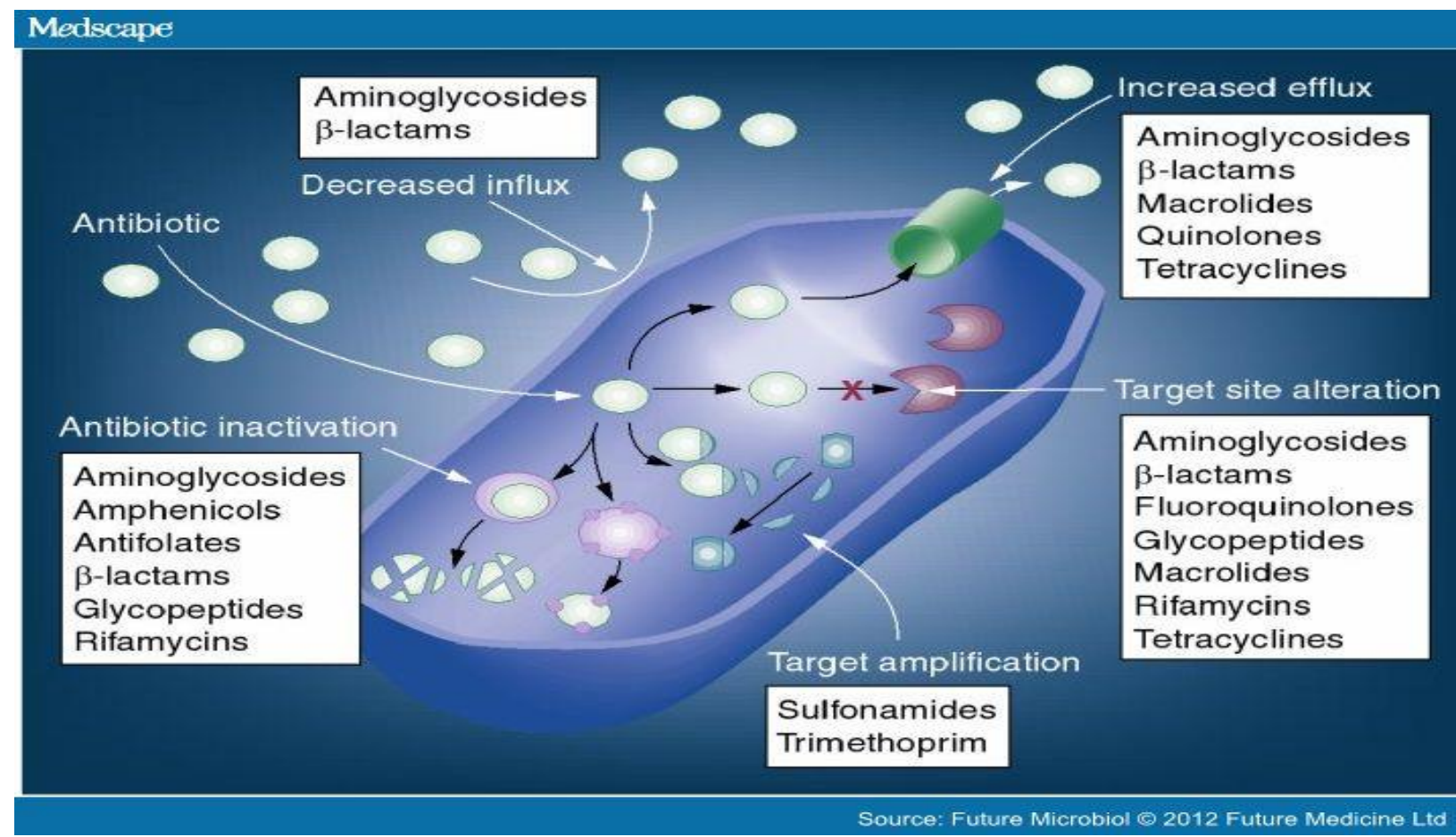

\section{Aminoglycoside resistance}

Furthermore, Enterococcus species are essentially resistant to different aminoglycosides group due to reduced cellular permeability of these agents, however this can be overcome with the adding of a cell wall acting agent as $\beta$-lactam, which enhance the entry of the aminoglycoside into the cell. In 1979 in the United States, the high level resistance (HLR) to gentamicin was established in both E. faecalis and E. faecium, and was follow rapidly by the isolation of HLR to both gentamicin and streptomycin in 1983 (Mederski-Samoraj and Murray, 1983). MICs of E. faecalis, differ for the aminoglycosides, with the highest degree of resistance was seen to streptomycin (MIC up to $500 \mu \mathrm{g} / \mathrm{ml}$ ) (Hollenbeck and Rice, 2012).

In Kingdom of Saudi Arabia, El-Kersh et al., (2016) indicated that the HLR to Gentamycin and streptomycin for different E. faecalis isolates were $25 \%$ and $11 \%$ respectively. In addition, Yezli et al., (2012) in Saudi Arabia illustrated that VRE has been detected against E. faecalis and E. faecium isolates in addition to with high level resistance was noticed to penicillin, sulfamethoxazole, macrolides, tetracycline, and aminoglycosides. In Ethiopia, Abamecha et al., (2015) found that out of 114 examined Enterococcus species, 41 $(36 \%)$ were resistant to ampicillin, 62 (54.4\%) to streptomycin and $39(34.2 \%)$ to gentamycin. Moreover, a highest degree of VRE faecium strains in the USA showed HLR to ampicillin, while maximum VRE faecalis strains continue susceptible to ampicillin (Driscol et al., 2015).

HLR to aminoglycosides is acquired out of two techniques of resistance: alteration of ribosomal engagement places and the manufacture of aminoglycoside modulate enzymes. Gentamicin or streptomycin is the recommended synergistic agents for usage 
with $\beta$-lactams to get bactericidal action. Eliopoulos (1993) indicated that the presence of HLR to aminoglycosides terminates the bactericidal action found with $\beta$-lactam and aminoglycoside synergy in medical pursuit. An increased frequency of elevation level of resistance to aminoglycoside antibiotics (MIC $>8,000 \mu \mathrm{g} / \mathrm{mL})$ in medical isolates of enterococci has been described which were also resistant to synergism with the penicillins. Mittal et al., (2016) demonstrated that the emergence of multidrug resistant enterococci to frequently utilized antimicrobial agents, e.g., aminoglycosides and cephalosporin's, is due to their capability to achieve and transfer the drug resistance gene, leading to increase the level aminoglycoside (HLAR) and glycopeptide resistance against enterococci. In Germany, Werner et al., (2012) stated that 64 E.faecalis and 37 E. faecium isolates did not show a particular multi resistance phenotype and resistances to glycopeptides and antibiotics. Moreover, in India, Vinodkumar et al., (2011) conveyed that a total of $65.6 \%$ of Enterococcus spp. showed HLAR.

\section{$\beta$-lactam resistance}

Enterococci apply a squat level intrinsic resistance to $\beta$-lactams due to penicillinbinding proteins (PBPs) with a squat empathy for these agents. Related to streptococci, $E$. faecalis is 10-100-fold less sensitive to penicillin, and matched to E. faecalis, $E$. faecium is 4-16fold less susceptible. Consequently, enterococci are tolerant to of the various $\beta$-lactam antibiotics, Nevertheless, if bactericidal action is required to treat severe infections such as endocarditis or meningitis, a synergistic bactericidal mixture of a $\beta$ lactam with an aminoglycoside can be utilized (Arias et al., 2010). High-level $\beta$-lactam resistance in enterococci is primarily due to two main techniques: the production of lowaffinity PBP5, or the production of $\beta$ - lactamases. Overproduction of PBP5 with low-affinity compulsory to $\beta$-lactams is distinguishing of $E$. faecium but unusual amongst E. faecalis. Actually, in the US most VRE faecium strains express high-level resistance (HLR) to ampicillin, whereas several VRE faecalis strains continue sensitivity to ampicillin. The production of $\beta$ lactamases is rare in Enterococcus species, nevertheless they can be a precursor of HLR by hydrolyzing $\beta$-lactams earlier they reach their target in the cell wall. It is practically worldwide due to E. faecalis strains and is constitutive and inoculum dependent (Cattoir et al., 2013).

E. faecalis chromosome does not comprise any extra glycosyl transferase-related genes, these comments designate that glycan chain polymerization in the triple mutant is did by a novel type of glycosyl transferase. The last enzyme was not reserved by moenomycin, subsequently deletion of the three classes A PBP genes led to high-level resistance to this glycosyl transferase inhibitor (Arbeloa et al., 2004). Enterococci have an intrinsic low vulnerability or resistance to $\beta$-lactams. Enterococcus faecalis naturally has least inhibitory concentricity (MICs) for penicillin of $2-8 \mathrm{mg} \mathrm{L}$, these significant human microorganisms have been the topic of intense molecular revisions, together with Enterococcus hirae, which is more of a veterinary anxiety (Hujer et al., 2005).

In USA, Smith et al., (2015) illustrated that Enterococcus faecalis $(E f c)$ and Enterococcus faecium (Efm) are regularly resistant to different antibiotics such as vancomycin and $\beta$-lactams (BLs). Fifteen $E f c$ and $20 \mathrm{Efm}$ strains were assessed for daptomycin improvement by mixture MICs. Daptomycin MICs were found by micro dilution in the absence and presence of ceftaroline, ertapenem, cefepime, ceftriaxone, cefotaxime, cefazolin and ampicillin. 
Phenotypic, molecular and mass spectrometry identification of $\boldsymbol{E}$. faecalis

\section{Phynotypic identification by Vitek2 compact system}

VITEK 2 cards which includes tests for Antimicrobial Susceptibility Testing (AST), which are FDA approved. The Vitek 2 AST (BioMe'rieux Vitek 2, France) uses Cefotaxime and Ceftazidime, only (at 0.5 $\mu \mathrm{g} / \mathrm{mL}$ ) and in mixture with Clavulanic acid (4 $\mu \mathrm{g} / \mathrm{mL})$. Inoculation of the cards is identical to that performed for steady VITEK 2 cards. Analysis of all wells is achieved mechanically once the growth control well has got a set threshold (4-15 hours of incubation). A predetermined reduction in the growth of the Cefotaxime or Ceftazidime wells comprising Clavulanic acid, compared with the level of growth in the well with the Cephalosporin alone, shows occurrence of ESBLs. Sensitivity and specificity of the technique out do 90\% (Winstanley and Courvalin, 2011).

\section{Molecular identification by PCR assay}

The aim of the polymerase chain reaction (PCR) is to identify and describe genes. PCR is an in vitro technique for amplifying a DNA sequence via a heat stable polymerase and two primers, one complementary to the $(+)$ strand at one end of the sequence to be amplified and the other complementary to the (+) strand at the other end. The recently synthesized DNA strands then assist as templates for the similar primers and succeeding rounds of primer annealing; strand elongation and dissociation harvest a greatly particular amplification of the sequence. PCR can be used in ecological observing assays to discover the presence or nonexistence of a DNA sequence in a sample, for example, a gene particular for an infectious viral particle or bacterium (Olsen, 2012). It is developed by
Kary Mullis in the 1980s. PCR is established on using the capability of DNA polymerase to manufacture new strand of DNA complementary to the existing template strand. In order to DNA polymerase can add a nucleotide one onto a preexisting 3 '-OH group; it requests a primer to which it can add the first nucleotide. This obligation makes it potential to delineate a particular area of template sequence that the investigator wants to amplify. Aboud et al., (2013) indicated that at the ending of the PCR response, the particular sequence will be accrued in billions of copies (amplicons).

By way of the heat, degree in the tube passes into the $\mathrm{T}_{\mathrm{m}}$ range and settles at the $\mathrm{Ta}$ temperature, the greatest probable number of primer molecules relative to the number of obtainable targets will have found those targets and will lay down in stable duplexes (Carr and Moore, 2012). Agarose gel electrophoresis is employed for size parting of the PCR output. The size(s) of PCR products is determined by comparison with a DNA ladder (a molecular weight marker), which comprises DNA fragments of identified size, run on the gel alongside the PCR products (Lee et al., 2012). In Germany, Werner et al., (2012) described that Molecular typing of the 64 isolates of $E$. faecalis showed three PFGE clusters of associated strains represented by 3 MLST types (ST40, ST211, ST268). In China, Sun et al., (2012) demonstrated that $E$. faecalis showed vancomycin and teicoplanin MIC results at $\geq 256 \mu \mathrm{g} / \mathrm{mL}$ and harbored vanA, excluding for 1vanB-carrying strain (MIC, 32 and $1 \mu \mathrm{g} / \mathrm{mL}$, correspondingly).In addition, in USA, Ferguson et al., (2016) stated that multiplex PCR was used to liken the delivery of virulence genes amongst $E$. faecalis and $E$. faecium isolated from coasts in Southern California and Puerto Rico to isolates from potential foundations counting humans, animals, birds, and plants. All 5 virulence genes were discovering in $E$. 
faecalis and E. faecium from coastline water, typically amongst $E$. faecalis. gelE was the maximum joint amongst isolates from all exporters types. In Iran, Honarm et al., (2012) established that routine analysis and PCR for all inoculated blood samples with $\geq 5 \mathrm{cfu} / \mathrm{ml}$ was positive. Meanwhile for PCR and routine assays was ten hours and five days, respectively PCR is a further rapid and sensitive assay for simultaneous discovery and description for E.faecalis, and determination of its sensitivity pattern to vancomycin.

In Germany, Dalpke et al., (2016) stated that the susceptibilities of the various PCR formats were 84 to $100 \%$ for vanA and 83.7 to $100 \%$ for $v a n B$; specificities were 96.8 to $100 \%$ for vanA and 81.8 to $97 \%$ for vanB. In China, He et al., (2016) indicated that nine optrA-carrying plasmids were conjugated into E. faecalis $\mathrm{JH} 2-2$ and the trans conjugants exhibited the optrA-associated phenotype.

The specific and rapid detection and quantification of ace, esp and gelE genes compared to conventional PCR assays, thus allowing the rapid and direct safety assessment of Enterococcus genus in food samples (Abouelnage et al., 2016). In Serbia, Stojanovic et al., (2014) indicated that E. faecalis was discovered in $49 \%$ (25/51), When individuality was made between the intracanal medications, there was an important variance in the number of PCR positive samples between $\mathrm{S} 1$ and $\mathrm{S} 2, \mathrm{~S} 1$ and S3, but not between S2 and S3 samples. FURLANETO-MAIA L et al., (2014) in Sao Paulo found that the PCR-based assay, the van (A) gene was detected in $100 \%$ of vancomycin resistant enterococci. This evaluation is simple to conduct and steadfast in the identification of clinically pertinent enterococci. The data acquired supported the requirement for a development of the automated system to detect some enterococci.
Proteomic identification by Mass Matrix assisted laser desorption/ionization (MALDI)

The term matrix assisted laser desorption ionization (MALDI) was invented in 1985 by Franz Hillenkamp, Michael Karas and their colleagues (Karas et al., 1985). Based biotyping is an emerging method for high throughput and quick bacterial ID. Due to its comparatively greater accuracy, inclusive database of clinically significant bacteria and low price compared to other bacterial ID techniques, MALDI has started changing current applies prevalent in clinical diagnosis. Nevertheless, applicability of MALDI in the area of bacterial research is still partial mostly due to the absence of data on non-clinical bacteria (Alatoom et al., 2011). MatrixAssisted Laser Desorption/Ionization Timeof-Flight Mass-Spectrometry (MALDI -TOF MS) is a quick and reliable method for microbial identification as most results gotby this are like to that of $16 \mathrm{~S}$ rRNA gene sequence analysis but at a quick rate and at a lesser price. This method is based on fingerprinting analyses of mainly ribosomal proteins, which are manufactured under all growth circumstances and are the most plentiful cellular proteins (Rahi et al., 2016). MALDI-TOF MS has been used to characterize a wide variety of bacteria including bacteria, fungi, and viruses the competence of MALDI-TOF to quickly characterize bacteria favors its potential uses in multiple areas including medical diagnostics, biodefense, ecological monitoring, and food quality control. MALDI-TOF MS is appropriate for highthroughput and quick bacterial identification at low prices and is a different for conventional laboratory biochemical and molecular identification systems (Giebel et al., 2010; ElBehiry et al., 2014; Elbehiry et al., 2016). In Germany, Werner et al., (2012) indicated that the conventional and MALDI 
TOF MS analyses identified 64 Enterococcus faecalis and 37 Enterococcus faeciumisolates, which were confirmed by species-specific PCRs. In Zagreb, Dobranic et al., (2016) stated that MALDI-TOF MS identification presented $100 \%$ concordance with API 20 Strep in the identification of Enterococcus faecalis.

\section{References}

Abamecha, A., Wondafrash, B., and Abdissa, A. 2015. Antimicrobial resistance profile of Enterococcus species isolated from intestinal tracts of hospitalized patients in Jimma, Ethiopia. BMC Research. 8:213

Aboud, M., Oh, H.H., McCord, B. 2013. Rapid direct PCR for forensic genotyping in under 25 min. Electrophoresis.34(11):1539-1547.

Abouelnage, M., Lamas, A., Guarddon, M., Osman, M., Miranda, M., and Cepeda, A. 2016. Assessment of food safety using a new real-time PCR assay for detection and quantification of virulence factors of enterococci in food samples. JOAM. DOI: 10.1111/jam.13306.

Alatoom, A. A., Cunningham, S. A., Ihde, S. M., Mandrekar, J., and Patel, R. 2011. Comparison of direct colony method versus extraction method for identification of grampositive cocci by use of Bruker Biotyper matrix-assisted laser desorption ionizationtime of flight mass spectrometry. J. Clin. Microbiol. 49: 868-2873.

Alzahrani, O.H., Badahdah, Y.S., Bamakrid, M.S., Alfayez, A.S., Alsaeedi, M.S., Mansouri, A.M., and Alzahrani, A.H. 2013. The Diabetic Foot Research in Arabs' Countries. OJEMD. 3(3): 157-165.

Amberpet, R., Sistla, S., Parija, S.M., and Thabah, M.M. 2016. Screening for Intestinal Colonization with Vancomycin Resistant Enterococci and Associated Risk Factors among Patients Admitted to an Adult Intensive Care Unit of a Large Teaching Hospital. JCDR. 10(9): 6-9.

Anvarinejad, M., Pouladfar, G., Japoni, A., Bolandparvaz, S., Satiary, Z., Abbasi, P., and Mardaneh, J. 2015. Isolation and Antibiotic Susceptibility of the Microorganisms Isolated from Diabetic Foot Infections in Nemazee Hospital, Southern Iran. Journal of Pathogens.ID 3287967

Arbeloa, A., Segal, H., Hugonnet, J.E., Josseaume, N., Dubost, L., Brouard, J.P., Gutmann, L., Mengin-Lecreulx, D., and Arthur, M. 2004. Role of class A penicillinbinding proteins inPBP5-mediated betalactam resistance in Enterococcus faecalis. J Bacteriol.186(5):1221-8.

Arias, C.A., Contreras, G.A., and Murray, B.E. 2016. Management of multidrug-resistant enterococcal infections. Clin Microbiol Infect.16(6):555-562.

Berlanga, J., Cibrian, D., Guillén, I., Freyre, F., Alba, J.S., and López-Saura, P. 2005. Methylglyoxal administration induces diabetes-like microvascular changes and perturbs the healing process of cutaneous wounds. ClinSci (Lond), 109(1):83-95.

Bhatt, M., Sahni, B., Praharaj, S., Grover, C., Kumar, C., Chaudhari, S., and Khajuria, A. 2014. Detection of glycopeptide resistance genes in enterococci by multiplex PCR. MJAFI. 71 (1):43-47.

Biswas P.P., Aninda, and Sen, S.D. 2016. Molecular Characterization of Virulence Genes in Vancomycin-Resistant and Vancomycin-Sensitive Enterococci. J Glob Infect Dis. 8(1): 16-24

Brechow, A., Slesaczeck, T., and Münch, D. 2013. Improving major amputation rates in the multicomplex diabetic foot patient: focus on the severity of peripheral arterial disease. Therapeutic Advances in Endocrinology and Metabolism. 4 (3): 83-94.

Cardona, A.F., and Wilson, S.E. 2015. Skin and Soft-Tissue Infections: A Critical Review and the Role of Telavancin in Their Treatment. Clin Infect Dis. 61 (2): 69-78.

Carr, A.C., Moore, S.D. 2012. Lucia, Alejandro, ed. "Robust quantification of polymerase chain reactions using global fitting". PLOS ONE. 7 (5): e37640.

Cattoir, V., and Leclercq, R. 2013. Twenty-five years of shared life with vancomycinresistant enterococci: is it time to divorce? J Antimicrob Chemother.68(4):731-742.

Centers for Disease Control and Prevention. 2011. VRE in Healthcare Settings, Retrieved from 
https://www.cdc.gov/hai/organisms/vre/vre.ht $\mathrm{ml}$

Centers for Disease Control Preventio. Vancomycin-resistant Staphylococcus aureus-Pennsylvania, 2002. MMWR Morb Mortal Wkly Rep. 51:902

Chang, S., Sievert, D.M., and Hageman, J.C. 2003. Infection with vancomycin-resistant Staphylococcus aureus containing the vanA resistance gene. N Engl J Med.348(14):13421347.

Chouchania, C., El Salabib, A., Marrakchia, R., Ferchichid, L., and Walshb, T.R. 2012. First report of mefA and $\mathrm{msrA} / \mathrm{msrB}$ multidrug efflux pumps associated with blaTEM-1 $\beta$ lactamase in Enterococcus faecalis. International Journal of Infectious Diseases. 16(2):104-109.

Comerlato, C.B., de Resende, M.C., Caierao, J., and Azevedo, P.A. 2013. Presence of virulence factors in Enterococcus faecalis and Enterococcus faecium susceptible and resistant to vancomycin. Mem Inst Oswaldo Cruz. 108(5): 590-595.

Dalpke, A.H., Hofko, M., and Zimmermann, S. 2016. Development of a Real-Time PCR Protocol Requiring Minimal Handling for Detection of Vancomycin-Resistant Enterococci with the Fully Automated BD Max System. J. Clin. Microbiol. 54 (9): 2321-2329.

Davies, J. and Davies, D. 2010. Origins and Evolution of Antibiotic Resistance. Microbiol. Mol. Biol. Rev. 74 (3): 417-433.

Den Engelsen, C., van der Werf, C., Matute, A.J., Delgado, E., Schurink, C.A., and Hoepelman, A.I. 2009. Infectious diseases and the use of antibiotics in outpatients at the emergency department of the University Hospital of León, Nicaragua. Int J Infect. 3(3):349-354.

Dobranic, V., Kazazic, S., Filipovic, I., Mikulec, N., and Zdolec, N. 2016. Composition of raw cow's milk microbiota and identification of enterococci by MALDI-TOF MS - short communication. Veterinarski arhiv. 86 (4): 581-590.

Doria, M., Rosado, V., Pacheco, L.R., Hernández, M., Betriu, A., Valls, J., Franch-Nadal, J., and Fernández Mauricio, D. 2016. Prevalence of Diabetic Foot Disease in Patients with Diabetes Mellitus under Renal
Replacement Therapy in Lleida, Spain. Biomed Res Int., ID 7217586.

Driscol, T., and Crank, C. 2015. Vancomycinresistant enterococcal infections: epidemiology, clinical manifestations, and optimal management. Infect Drug Resist. 8: 217-230.

El Behiry A., Zahran R.N., Marzouk E., Al-Dabib M. 2014. Phenotypical and mass spectral assessment methods for identification of some contagious mastitis pathogens. American J Microbiol. 5: 1-10.

Elbehiry, A., Al-Dubaib, M., Marzouk, E., Osman, S., and Edrees, H. 2016. Performance of MALDI biotyper compared with Vitek (TM) 2 compact system for fast identification and discrimination of Staphylococcus species isolated from bovine mastitis Microbiologyopen. 5(6): 1061-1070.

Eliopoulos, G.M. 1993. Aminoglycoside resistant enterococcal endocarditis. Infect Dis Clin North Am.7(1):117-133.

Eliopoulos, G.M., and Gold, H.S. 2001. Vancomycin-Resistant Enterococci: Mechanisms and Clinical Observations. Clin Infect Dis.33 (2): 210-219.

El-Kersh, T.A., Marie, M.A., Al-Sheikh, Y.A., Al-Agamy, M.H., and Al-Bloushy, A.A. 2016. Prevalence and risk factors of early fecal carriage of Enterococcus faecalis and Staphylococcus spp and their antimicrobial resistant patterns among healthy neonates born in a hospital setting in central Saudi Arabia. Saudi Med J. 37(3): 280-287.

El-Tahawy, A.T. 2000. Bacteriology of diabetic foot infections., $\mathrm{MD}, \mathrm{PhD}$ (UK), Saudi Medical Journal. 21 (4): 344-347.

Enterococcus faecalis and Porphyromonas gingivalis in Infected Root Canals and Their Susceptibility to Endodontic Treatment Procedures: A Molecular Study. Srp Arh Celok Lek. 142(9-10):535-541.

Ferguson, D.M., Talavera, G.N., Hernández, L.R., Weisberg, S.B., Ambrose, R.F., and Jay, J.A. 2016. Virulence Genes among Enterococcus faecalis and Enterococcus faecium Isolated from Coastal Beaches and Human and Nonhuman Sources in Southern California and Puerto Rico. Journal of Pathogens. ID 3437214:7. 
Fisher, K., and Phillips, C. 2009. The ecology, epidemiology and virulence of Enterococcus. Microbiology. 155(6):1749-57.

Forbes, B.A., Sahm, D.F., and Weissfeld, A.S. 2014. Diagnostic Microbiology. 13th ed. Mosby.

Furlaneto-maia, L., Rocha, K., Siqueira, V., and Furlaneto, M. 2014. Comparison between automated system and pcr-based method for identification and antimicrobial susceptibility profile of clinical Enterococcus spp. Rev Inst Med Trop Sao Paulo. 56(2):97-103.

Giebel, R., Worden, C., Rust, S.M., Kleinheinz, G.T., Robbins, M. and Sandrin, T.R. 2010. Microbial fingerprinting using matrixassisted laser desorption ionization time-offlight mass spectrometry (MALDI-TOF MS) applications and challenges. Adv Appl Microbiol. 71: 149-184.

Gilmore, M.S., Clewell, D.B., Courvalin, P., Dunny G.M., Murray B.E., and Louis B. Rice L.S. 2002. The Enterococci: Pathogenesis, Molecular Biology, and Antibiotic Resistance and Infection Control. ISBN: 978-1-55581234-8.

Giridhara Upadhyaya, P. M., Umapathy, B. L., and Ravikumar, K. L. 2010. Comparative Study for the Presence of Enterococcal Virulence Factors Gelatinase, Hemolysin and Biofilm Among Clinical and Commensal Isolates of Enterococcus faecalis. J Lab Physicians. 2(2): 100-104.

Gooday, C., Murchison, R., and Dhatariya, K. 2014. Complex relationships requiring longterm follow-up: Obesity, bariatric surgeryinduced diabetic remission, and the diabetic foot. The Diabetic Foot Journal. 17 (1): 20-4.

Hartemann-Heurtier, A. J., Robert, S., Jacqueminet R. 2004. Diabetic foot ulcer and multidrug-resistant organisms: risk factors and impact. Diabet. Med. 21(7):710-5.

Hartemann-Heurtier, A., Robert, J., and Jacqueminet, S. 2004. Diabetic foot ulcer and multidrug-resistant organisms: risk factors and impact. Diabet Med. 21:710-5.

He, T., Shen, Y., Schwarz, S., Cai, J., Lv, Y., Li, J., FeBler, A., and Zhang, R. 2016. Genetic environment of the transferable oxazolidinone/phenicol resistance gene optrA in Enterococcus faecalis isolates of human and animal origin. J. Antimicrob. Chemother. doi: 10.1093 .

Hollenbeck, B.L. and Rice, L.B. 2012. Intrinsic and acquired resistance mechanisms in Enterococcus. Virulence.15. 3(5): 421-569.

Honarm, H., Ghavidel, M.F., Nikokar, I., Taromsari, M.R. 2012. Evaluation of a PCR Assay to Detect Enterococcus faecalis in Blood and Determine Glycopeptides Resistance Genes: Van A and Van B. Iran J Med Sci. 37(3): 194-199.

Hujer, A.M., Kania, M., Gerken, T., Anderson, V.E., Buynak, J.D., Ge, X., Caspers, P., Page, M.G., Rice, L.B.and Bonomo, R.A. 2005. Structure-activity relationships of different $\beta$ lactam antibiotics against a soluble form of Enterococcus faecium PBP5, a type II bacterial transpeptidase. Antimicrob Agents Chemother.49: 612-618.

John, V.U., and Carvalho, J. 2011. Enterococcus: review of its physiology, pathogenesis, diseases and the challenges it poses for clinical microbiology. J. Front. Biol., 6: 357.

Karas, M., Bachmann, D., and Hillenkamp, F. 1985. "Influence of the Wavelength in HighIrradiance Ultraviolet Laser Desorption Mass Spectrometry of Organic Molecules". Analytical Chemistry. 57 (14): 2935-9.

Karimzadeh, I., Mirzaee, M. N. Sadeghimanesh Sagheb, M.M. 2016. Antimicrobial resistance pattern of Gram-positive bacteria during three consecutive years at the nephrology ward of a tertiary referral hospital in Shiraz, Southwest Iran. JRPP. 5(4): 238-247.

Klibi, N., Ben Slama, K., Sáenz, Y., Masmoudi, A., Zanetti, S., Sechi, L.A., Boudabous, A., and Torresb, C. 2007. Detection of virulence factors in high-level gentamicin-resistant Enterococcus faecalis and Enterococcus faecium isolates from a Tunisian hospital. Canadian Journal of Microbiology. 53(3): 372-379.

Koch, S., Hufnage, M., Theilacker, C., and Huebner, J. 2004. Enterococcal infections: host response, therapeutic, and prophylactic possibilities. Vaccine, 22:822-30.

Kow, N., and Ferzandi, T.R. 2014. Enterococcus osteomyelitis secondary to pyelonephritis. International Urogynecology Journal. 24(4):691-692. 
Lawrence, J.G. 2005. Horizontal and Vertical Gene Transfer: The Life History of Pathogens. Contrib. Microbiol. 12: 255-271.

Lebreton, F., Riboulet-Bisson, E., Serror, P., Sanguinetti, M., Posteraro, B., Torelli, R., Hartke, A., Auffray, Y., and Giard, J.C. 2009. Ace, Which encodes an adhesin in Enterococcus faecalis, is regulated by Ers and is involved in virulence. Infect Immun. 77(7):2832-9.

Lee, P.Y., Costumbrado, J., Hsu, C.Y., and Kim, Y.H. 2012. Agarose Gel Electrophoresis for the Separation of DNA Fragments. J. Vis. Exp. (62), e3923.

Lipsky, B.A., Richard, J.L., and Lavigne, J.P. 2013. Diabetic foot ulcer microbiome: one small step for molecular microbiology One giant leap for understanding diabetic foot ulcers? Diabetes. 62(3):679-81.

Lochan, H., Moodle, C., Rip, D., Bamford, C., Hendricks, M., Davidson, A., and Eley, B. 2016. Emergence of vancomycin-resistant Enterococcus at a tertiary paediatric hospital in South Africa. South African Medical Journal. 106(6):562-566.

Mainardi, J.L., Villet, R., Bugg, T.D., Mayer, C., and Arthur, M. 2008. Evolution of peptidoglycan biosynthesis under the selective pressure of antibiotics in Grampositive bacteria. FEMS Microbiol Rev.32(2):386-408.

Malachowa, N. and DeLeo, F.R. 2010. Mobile genetic elements of Staphylococcus aureus. Cell Mol Life Sci. 67(18): 3057-3071.

Martinez, J.L. and Baquero, F. 2002. Interactions among Strategies Associated with Bacterial Infection: Pathogenicity, Epidemicity, and Antibiotic Resistance. Clin. Microbiol. Rev. 15(4): 647-679.

Mathangi, T., and Prabhakaran, P. 2013. Prevalence of Bacteria Isolated from Type 2 Diabetic Foot Ulcers and the Antibiotic Susceptibility Pattern. Int.J.Curr.Microbiol.App. 2: 329-337.

McInnes, A.D. 2012. Diabetic foot disease in the United Kingdom: about time to put feet first, Journal of Foot and Ankle Research. 26 (5): 1757-1146.

Medeiros, A.W., Pereira, R.I., Oliveira, D.V., Martins, P.D., dAzevedo, P.A., Van der Sand, S., Frazzon, J., and Frazzon, A.P. 2014.
Molecular detection of virulence factors among food and clinical Enterococcus faecalis strains in South Brazil. Braz $\mathbf{J}$ Microbiol. 45(1): 327-332.

Mederski-Samoraj, B.D., and Murray, B.E. 1983. High-level resistance to gentamicin in clinical isolates of enterococci. J Infect Dis.147(4):751-757.

Miller, W.R., Munita, J.M., and Arias, C.A. 2014. Mechanisms of antibiotic resistance in enterococci. Expert Rev Anti Infect Ther. 12(10): 1221-1236.

Miro, J.M., Pericas, J.M., and Rio, A.D. 2013. A New Era for Treating Enterococcus Faecalis Endocarditis: Ampicillin plus Short-Course Gentamicin or Ampicillin plus Ceftriaxone; that is the Question! Published online. doi: 10.1161/CIRCULATIONAHA.113.002431.

Mittal, S., Singla, P., Deep, A., Bala, K., Sikka, R., Garg, M., and Chaudhary, U. 2016. Vancomycin and High Level Aminoglycoside Resistance in Enterococcus spp. in a Tertiary Health Care Centre: A Therapeutic Concern. Journal of Pathogens. ID 8262561.

Moses, V., Jerobin, J., Nair, A., Sathyendara, S., Balaji, V., George, A., and Peter, J.V. 2012. Enterococcal Bacteremia is Associated with Prolonged Stay in the Medical Intensive Care Unit. J Glob Infect Dis., 4(1): 26-30.

Olawale, K.O., Fadiora, S.O., and Taiwo, S.S. 2011. Prevalence of Hospital-Acquired Enterococci Infections in Two Primary-Care Hospitals in Osogbo, Southwestern Nigeria. Afr J Infect Dis., 5(2): 40-46.

Olsen, J.L. 2012. Polymerase Chain Reaction. Encyclopedia of Immunotoxicology. 715720.

Palmer, K.L., Kos, V.N., and Gilmore, M.S. 2010. Horizontal gene transfer and the genomics of enterococcal antibiotic resistance. Curr Opin Microbiol. 13(5):632-9.

Perich, A.P., González, R.M., Valdés, E., and Arranz, M.C., 2010. Desarrollo de diabetes mellitus en pacientes con tolerancia a la glucosaalterada: Seguimiento de 18 años. Rev Cubana Endocrinol, 13(2): 0-0.

Praharaj, I., Sujatha, S., Parija, S. 2013. Phenotypic \& genotypic characterization of vancomycin resistant Enterococcus isolates 
from clinical specimens. Indian $\mathrm{J}$ Med Res.138(4): 549-556.

Quilici, M.T., Del Fiol, F., Vieira, A.E., and Toledo, M.I. 2016. Risk Factors for Foot Amputation in Patients Hospitalized for Diabetic Foot Infection. Journal of Diabetes Research, ID 8931508, 8.

Rahi, P., Prakash, O., and Shouche, Y. 2016. Matrix-Assisted Laser Desorption/Ionization Time-of-Flight Mass-Spectrometry (MALDITOF MS) Based Microbial Identifications: Challenges and Scopes for Microbial Ecologists. Front Microbiol. 7: 1359.

Raja, N.S. 2007. Microbiology of diabetic foot infections in a teaching hospital in Malaysia: a retrospective study of 194 cases. J Microbiol. Immunol. Infect.40(1):39-44.

Rajkumari, N., Mathur, P., and Misra, M.C. 2014. Soft tissue and wound infections due to Enterococcus spp. among hospitalized trauma patients in a developing country. $\mathrm{J}$ Global Infect Dis. (6):189-93.

Ray, G.T., Suaya, J.A., and Baxter, R. 2013. Incidence, microbiology, and patient characteristics of skin and soft-tissue infections in a U.S. population: a retrospective population-based study BMC Infectious Diseases, 13:252.

Rengaraj, R., Mariappan, S., Sekar, U., and Kamalanadhan, A. 2016. Detection of Vancomycin

Resistance among Enterococcus faecalis and Staphylococcus aureus. J Clin Diagn Res. 10(2): 4-6.

Rezende, K.F., Ferraz, M.B., and Malerbi, D.A. 2010. "Predicted annual costs for in patients with diabetes and foot ulcers in a developing country - a simulation of the current situation in Brazil," Diabetic Medicine. 27(1):109112.

Saba Copur, S., Şahin, F., and Goçmen, J.S. 2016. Determination of virulence and multidrug resistance genes with polymerase chain reaction method in vancomycin sensitive and resistant enterococci isolated from clinical samples. Turk J Med Sci. 46(3):877-91.

Santos, I.C., Sobreira, C.M., Nunes, E.N., and Morais, M.C. 2013. "The prevalence and factors associated with diabetic foot amputations," Ciencia e Saude Coletiva.18 (10):3007-3014.
Schmieder, R., and Edwards, R. 2012. Insights into Antibiotic Resistance through Metagenomic Approaches. Future Microbiol. 7(1):73-89.

Semedo-Lemsaddek, T., Mottola, C., AlvesBarroco, C., Cavaco-Silva, P., Tavares, L., and Oliveira M. 2016. Characterization of multidrug-resistant diabetic foot ulcer enterococci. Enferm Infecc Microbiol Clin., 34(2):114-6.

Shankar, V., Baghdayan, A.S., Huycke, M.M., Lindahl, G., and Gilmore, M.S. 1999. Infection-Derived Enterococcus faecalisStrains Are Enriched in esp, a Gene Encoding a Novel Surface Protein. Infect. Immun. 67(1): 193-200.

Sievert, D.M., Ricks, P., Edwards, J.R., Schneider, A., Patel, J., Srinivasan, A., Kallen, A., Limbago, B., and Fridkin, S. 2013. National Healthcare Safety Network (NHSN) Team and Participating NHSN Facilities. Infect Control Hosp Epidemiol. 34(1):1-14.

Smith, J.R., Barber, K.E., Raut, A., Aboutaleb, M., Sakoulas, G., and Rybak, M.J. 2015. $\beta$ Lactam combinations with daptomycin provide synergy against vancomycin resistant Enterococcus faecalis and Enterococcus faecium. J Antimicrob Chemother.; 70(6): 1738-43.

Soheili, S., Ghafourian, S., Sekawi, Z., Neela, V., Sadeghifard, N., Ramli, R., and Hamat, R.A. 2014. Wide Distribution of Virulence Genes among Enterococcus faecium and Enterococcus faecalis Clinical Isolates. The Scientific World Journal. (2014) ID 623174:6

Stalker, M.J., Brash, M.L., Weisz, A., Ouckama, R.M., and Slavic, D. 2010. Arthritis and osteomyelitis associated with Enterococcus cecorum infection in broiler and broiler breeder chickens in Ontario, Canada Stalkerc. J Vet Diagn.22:643-645.

Stevens, D.L., Bisno, A.L., Chambers, H.F., Dellinger, E.P., Goldstein, E.J., and Gorbach, S.L. 2014. Practice guidelines for the diagnosis and management of skin and soft tissue infections: 2014 update by the Infectious Diseases Society of America. Clin Infect Dis. 59 (2):147-59.

Stojanovic, N., Krunic, J., Popovic, B., Stojicic, S., and Zivkovic, S. 2014. Prevalence of 
Sun, H., Wang, H., Xu, Y., Jones, R.N., Costello, A.J., Liu, Y., Li, G., Chen, M., and Mendes, R.E. 2012. Molecular characterization of vancomycin-resistant Enterococcus spp. clinical isolates recovered from hospitalized patients among several medical institutions in China. Diagn Microbiol Infect Dis.74(4):399403.

Tripathi, A., Shukla, S.K., Singh, A., and Prasad, K.N. 2016. Prevalence, outcome and risk factor associated with vancomycin-resistant Enterococcus faecalis and Enterococcus faecium at a Tertiary Care Hospital in Northern India. Indian Journal of Medical Microbiology. 34(1): 38-45.

Turhan, V., Mutluoglu, M., Acar, A., Hatipoglu, M., Onem, Y., Uzun, G., Ay, H., Oncul, O., and Gorenek, L. 2013. Increasing incidence of Gram-negative organisms in bacterial agents isolated from diabetic foot ulcers. JIDC. 10(7): doi:10.3855/jidc.2967.

Van Hoek, A., Mevius, D., Guerra, B., Mullany, P., Roberts, A.P. and Aarts, H.J.M. 2011. Acquired Antibiotic Resistance Genes: An Overview. Front Microbiol. 2(203): doi:0.3389/fmicb.2011.00203.

Vinodkumar,.CS., Srinivasa, H., Basavarajappa, K.G., Geethalakshmi, S., and Bandekar, N. 2011. Isolation of bacteriophages to multidrug resistant Enterococci obtained from diabetic foot: a novel antimicrobial agent waiting in the shelf?. Indian J Pathol Microbiol.54(1):90-5.

Vinodkumar, C.S., Srinivasa, H., Basavarajappa, K.G., Geethalakshmi, S., and Bandekar, N. 2011. Isolation of bacteriophages to multidrug resistant Enterococci obtained from diabetic foot: a novel antimicrobial agent waiting in the shelf? Indian $\mathbf{J}$ Pathol Microbiol. 54(1):90-5.
Vogan, A.A. and Higgs, P.G. 2011. The advantages and disadvantages of horizontal gene transfer and the emergence of the first species. Biology Direct. 6(1): doi: 10.1186/1745-6150-6-1.

Werner, G., Fleige, C., Fessler, A.T., Timke, M., Kostrzewa, M., Zischka, M., Peters, T. Kaspar, H., and Schwarz, S. 2012. Improved identification including MALDI-TOF mass spectrometry analysis of group D streptococci from bovine mastitis and subsequent molecular characterization of corresponding Enterococcus faecalis and Enterococcus faecium isolates. Vet Microbiol.160(1-2):162-9.

Winstanley, T. and Courvalin, P. 2011. Expert Systems in Clinical Microbiology. Clin. Microbiol. Rev. 24 (3): 515-556.

Yameen, M.A., Iram, S., Mannan, A., Khan, S.A., and Akhtar, N. 2013. Nasal and perirectal colonization of vancomycin sensitive and resistant enterococci in patients of paediatrics ICU (PICU) of tertiary health care facilities. BMC Infect Dis. 13:156.

Yezli, S., Shibl, A.M., Livermore, D.M., and Memish, Z.A. 2012. Antimicrobial resistance among Gram-positive pathogens in Saudi Arabia. J Chemother. 24(3):125-36.

Zemann, W., Feichtinger, M., Pau, M., and Kärcher, H. 2011. Primary osteomyelitis of the mandibular condyle - a rare case. Oral and Maxillofacial Surgery. 15(2): 109-111.

Zhanel, G.G., Adam, H.J., and Baxter, M.R. 2013. Canadian Antimicrobial Resistance Alliance. Antimicrobial susceptibility of 22746 pathogens from Canadian hospitals: results of the CANWARD 2007-2011 study. J Antimicrob Chemother. 68(1): 7-22.

\section{How to cite this article:}

Ahmad Abdulrahman AL Bloushy and Ayman Elbehiry. 2018. History, Virulence Genes, Identification and Antimicrobial Resistance of Enterococcus faecalis Isolated from Diabetic Foot Patients. Int.J.Curr.Microbiol.App.Sci. 7(01): 2136-2154. doi: https://doi.org/10.20546/ijcmas.2018.701.258 